DOI: $10.17516 / 1997-1370-0756$

УДК 008, 81-119

\title{
Word-Formational Formant as a Tool of the Process of Native Speakers' Ethnocultural Identity (Case Study: Dialect Derivatives with the Formant -yш/a)
}

\author{
Liudmila A.Araeva ${ }^{a}$ and Anastasiya A. Lushpey*b \\ ${ }^{a}$ Kemerovo State University \\ Kemerovo, Russian Federation \\ ${ }^{b}$ Kemerovo State University of Culture and Arts \\ Kemerovo, Russian Federation
}

Received 15.03.2021, received in revised form 05.04.2021, accepted 21.05.2021

\begin{abstract}
Modern multicultural space is a result of globalisation processes at all levels of human activity. However, a complex of tendencies towards unification gives rise to academic interest in the study of language in the aspect of its functional characteristics as a way of forming ethnocultural entity of a linguistic community. Dialects are a specific language subsystem, which has its own unique units for the process of nomination of persons, artifacts and natural facts of the surrounding reality. Due to its sphere of functioning, the word-formation formant-yш/a is a linguistic unit that is used by the dialect speakers for an alternative to the literary language way of creating nouns denoting plants, animals, and fish. Derivative words with such a suffix represent the value paradigm, verbalised through the relevant for a person qualities of objects, such as taste, colour, shape, place of growth, and functional properties. The appeal to dialectal derivative vocabulary with the archaic suffix, which is not currently used in the literary Russian language, gives an opportunity to describe the cognitive processes of the linguistic creativity of the Russian-speaking population in terms of its typical and unique features.
\end{abstract}

Keywords: ethnocultural linguistic identity, culture, language, dialectal derivatives.

Research area: culturology.

Citation: Araeva, L.A., Lushpey, A.A. (2021). Word-formational formant as a tool of the process of native speakers' ethnocultural identity (case study: dialect derivatives with the formant $-\mathrm{yw} / \mathrm{a}$ ). J. Sib. Fed. Univ. Humanit. Soc. Sci., 14(6), 748-756. DOI: 10.17516/1997-1370-0756.

(c) Siberian Federal University. All rights reserved

* Corresponding author E-mail address: araeva@list.ru, ana1534@ya.ru ORCID: 0000-0002-8418-0453 (Lushpey) 


\title{
Словообразовательный формант как инструмент процесса этнокультурной идентичности носителей языка \\ (на материале диалектных дериватов с формантом -уш/а)
}

\section{Л.А.Араева ${ }^{\text {, }}$ А.А. Лушпей}

${ }^{a}$ Кемеровский государственный университет

Российская Федерачия, Кемерово

${ }^{6}$ Кемеровский государственный институт культуры

Российская Федерация, Кемерово

\begin{abstract}
Аннотация. Современное мультикультурное пространство является результатом процессов глобализации на всех уровнях жизнедеятельности человека. Однако совокупность тенденций к унификации порождает интерес ученых к исследованию языка в аспекте его функциональной характеристики как способа формирования этнокультурной общности языкового коллектива. Диалекты - особая подсистема языка, которая обладает своими уникальными единицами для процесса номинации лиц, артефактов и натурфактов окружающей действительности. Словообразовательный формант -уш/а в силу своей сферы функционирования представляет собой языковую единицу, которая используется носителями диалекта для альтернативного литературному языку способа создания имен существительных, обозначающих растения, животных, рыб. Производные слова с таким суффиксом репрезентируют ценностную парадигму, вербализованную через актуальные для человека качества предметов: вкус, цвет, форма, место произрастания, функциональные свойства. Обращение к диалектной производной лексике с архаичным суффиксом, который в настоящее время не используется в литературном русском языке, позволяет описать когнитивные процессы языкового творчества русскоязычного населения в аспекте его характерных и уникальных признаков.
\end{abstract}

Ключевые слова: этнокультурная языковая идентичность, культура, язык, диалектные дериваты.

Научная специальность: 24.00.00 - культурология.

\section{Введение}

Этнокультурная общность народа непосредственно связана с процессами его этнокультурной идентификации на языковом уровне. Соблюдение языковой нормы, усвоение синтагматических и парадигматических отношений на языковых уровнях способствуют «оязыковлению» культурного пространства народа. При этом носитель языка является, с одной стороны, воспринимающим, а с другой - порождающим субъектом номинации натурфактов и артефактов, входящих в оязыковленное пространство.
Включенный с рождения в такого рода пространство человек получает от него языковые средства - свернутую с помощью различных формантов информацию, позволяющую ему идентифицировать себя в культуре. Таким образом осуществляется ориентирование человека в культуре, которое включает такие виды культурной деятельности, как «выработка ценностных ориентаций, выделение смысловых моментов индивидуального бытия, формирование представлений о том, что есть Истина» (Astakhov, 2010: 20). В этом процессе самоопределения человека ведущую 
роль играет языковая идентификация, так как языковые единицы - это не просто носители информации, а коды культуры народа, позволяющие рассматривать язык как способ познания мира и самопознания. Язык - это и форма, и содержание, и структура этнической культуры. Как отмечает Б. Рассел, постигая устройство языка, мы многое узнаем об устройстве мира (Russel, 2000). Язык - это, прежде всего, важнейшее средство, обеспечивающее единство этнокультурного пространства; культурно-языковое пространство через предметы материальной культуры, фольклор, литературу, традиции, обычаи, ритуалы, феномены искусства маркирует пространство этнической культуры.

\section{Концептуальный базис исследования}

Представителями Кемеровской дериватологической школы за 27 лет существования написано более 1000 работ, посвященных анализу словообразовательных формантов в рамках таких словообразовательных категорий, как словообразовательный тип, словообразовательная ниша, многозначное производное слово, компактные пропозиционально связанные группы производных слов, оформленные с одним и тем же формантом, на материале русского литературного и диалектного языка, а также на материале телеутского, алтайского, киргизского, английского, китайского языков (Araeva, 2009; Araeva et al., 2015; Araeva et al., 2018; Evseeva, Kreydlin, 2017; Obraztsova, 2016; Osadchii, 2013; Proskurina, 2010; Falomkina, 2012 и др.). В своих работах, используя метод пропозициональнофреймового моделирования, исследователи выявили специфику языковой картины мира (ЯКМ) носителей исследуемых языков, обосновали значимость форманта в формировании и сохранении культурных традиций, особенностей познания мира диалектоносителями, а также представителями других народов. Наша работа способствует выявлению на основе анализа не проанализированной ранее нишы с формантом -уш/a/, функционирующей в русских народных говорах, особенностей фрагментов ЯКМ, их культурной значимости.

\section{Постановка проблемы}

В статье в пределах словообразовательной ниши с формантом -уш/а/ рассматривается класс номинаций натурфактов, в котором представлены свернутые суждения диалектоносителей о форме, вкусе, функциональной принадлежности окружающих их представителей флоры и фауны. Такие диалектные дериваты отличаются от научных терминов, что, несомненно, детерминировано на уровне различия диалектной картины мира и научной картины мира. Формант -уш/а/ в данном случае выступает как маркер диалектных слов, так как в литературном языке он участвует в образовании только лишь 7 слов. Рассмотрение специфики номинации объектов природного мира в диалектной картине мира носителя языка посредством специфичного и уникального форманта - вот тот аспект, на котором сосредотачиваются авторы статьи.

\section{Методы}

Для анализа материала используется описательный метод, включающий приемы наблюдения, сопоставления; метод сплошной выборки; метод межсистемной дополнительности; метод интроспекции, метод пропозиционального анализа. В качестве единиц для исследования выступают дериваты с формантом -уш/а/, извлеченные методом сплошной выборки из словарей русских народных говоров (в общей сложности обработано 109 томов, 1470 словарных статей с интересующим нас формантом).

\section{Обсуждение}

Интерес к изучению словообразовательных формантов непосредственно коррелирует с зарождением и развитием в отечественной лингвистике отдельного научного направления - словообразования. Активное развитие когнитивного словообразования как научного направления обусловило появление новых подходов к анализу деривационных единиц, что позволяет рассматривать их в многоаспект- 
ном, междисциплинарном измерении. Признание в качестве комплексной единицы словообразования словообразовательной ниши определяет ее как иерархически организованную структуру знаний, как способ хранения информации, содержащейся в мотивирующем и производном слове. С другой стороны, появление и обоснование в научном дискурсе междисциплинарного направления - культурологии - предоставляет исследователям диалектной лексики возможность выйди за рамки сугубо лингвистической дисциплины (словообразования) в пространство лингвокультурологическое.

Результатом синтеза лингвистического, философского и культурологического подходов стала идея этнокультурной идентичности народа, которая формируются посредством актуализации ценностей, заложенных в структуре языковых единиц. Формирование понятия «диалектная картина мира» явилось результатом и одновременно логичным продолжением процесса рассмотрения идиоэтнического языка как противоположного литературному, нормативному и кодифицированному. Диалект противопоставляется общенациональному языку не только по критерию отсутствия или наличия кодификации, но и по целому ряду других характеристик, среди которых отмечается архаичность, альтернативная форма освоения действительности, широкий спектр единиц для коннотативной окраски. Рассмотрение диалектизмов в словообразовательном аспекте обусловлено тем положением, что на уровне словообразовательных значений представлены в том или ином виде знания носителя языка об окружающей действительности, особого рода свернутые суждения о том или ином предмете. Важным структурным компонентом лексико-словообразовательного значения является формант, носитель не только словообразовательного, но и лексического значения. Среди широкого спектра формантов русского языка особый интерес исследователей вызывают архаичные суффиксы, функционирующие преимущественно в диалектной системе национального языка.
К их числу относится формант -уш/а, необходимый компонент номинации объектов окружающей действительности диалектоносителя. Эксплицированность такого рода дериватов в диалектной системе русского языка отражает процессы альтернативного познания окружающего мира человеком.

Анализируя представленный в диалектных словарях русского языка перечень производных слов с формантом -уш/а, мы выделяем в отдельную тематическую группу названия представителей флоры и фауны на основании их противопоставленности (по способу образования, актуализации значимого признака) названиям в литературной, нормативной, кодифицированной системе русского общенационального языка.

Характеризуя многообразный мир растений, носитель диалекта выбирает актуальные и значимые для него признаки: место произрастания, уровень сложности выращивания. Актуализация места произрастания посредством мотивирующей основы представлена в следующих дериватах: боровуша - сосна, растущая в бору (Slovar' russkikh narodnykh govorov, 1968: 108); дикуша - 1. гречиха; 2. растение Ribes Dikuscha Fisch., сем. крыжовниковых; смородина; 2. растение Brassica Napus L., сем. крестоцветных; брюква; 3. растение Pisum Tourn., сем. мотыльковых; горох; 4. растение Bunias L., сем. крестоцветных (Slovar' russkikh narodnykh govorov, 1972: 64-65).

Свернутое пропозициональное суждение о растении полисеманта дикуша является вербализованным носителем информации для следующих поколений. Интересен тот факт, что образованный от той же мотивированной основы дериват дикуша (птица Pelecanus, отряда пеликановых; пеликан, но уже обозначающий птицу) несет то же значение (Slovar' russkikh narodnykh govorov, 1972: 65).

Актуализация вкусовых качеств растения представлена в полисеманте горькуша: 1. растение Saussurea glomerate Poir, семейства сложноцветных; горькуша скученная (Slovar' russkikh narodnykh govorov, 1966: 94); 2. растение Centaurea jacea L., ce- 
мейство сложноцветных (Slovar' russkikh narodnykh govorov, 1970: 336); 3. растение Polygonum hydropiper L. сем. гречишных; водяной перец; 4. растение Polygonum scabrum Moench., сем. гречишных; горец шероховатый; 5. растение Arthemisia absinthium L., сем. сложноцветных; полынь горькая; 6. растение Serratula amara L., сем. сложноцветных; 7. растение Taraxacum officinale L., сем. сложноцветных; одуванчик аптечный; 8. растение Acroptilon picris С. А. М., сем. сложноцветных; горчак ползучий; 9. растение Hieracium umbellatum L., сем. сложноцветных; ястребинка зонтичная; 10. растение Inula britanica L., сем. сложноцветных; девясил британский; 11. растение Ranunculus acris L., сем. лютиковых; лютик едкий; 12. растение Hierochloa borealis R. et Sch., сем. злаковых; зубровка душистая; 13. растение Galium rubicides L., сем. маренных; подмаренник членистый; 14. растение Barbarea R. Вг., сем. крестоцветных; сурепица; 15. вишня с мелкими горьковатыми ягодами; 16. гриб Agaricus amarus, сыроежка; 17. рыба Cyprinus Idus, мелкая рыба, похожая на плотву; 18. рыба Rhodeus amarus (Slovar' russkikh narodnykh govorov, 1972: 82).

Многовалентный диалектный полисемант горькуиа в пределах одного словообразовательного типа демонстрирует тенденцию к номинации натурфактов окружающей действительности диалектоносителя через актуальные для него характеристики предмета. Знание о вкусовых характеристиках натурфакта помогает носителю диалекта в условиях повседневной жизни овладеть способами обращения с растениями, с рыбой для приготовления пищи и эликсиров. Тем самым диалектный дериват в силу своей бытовой функциональности, прагматичности противопоставляется деривату научной области знаний, который определяет общие онтологические свойства предметов согласно принятой научной классификации. Диалектные слова здесь способствуют формированию этнокультурной идентичности носителей диалекта, определяя и характеризуя окружающую действительность.
Актуализация цветового признака растения вербализована в следующих дериватах:

красноголуха и красноголуша - сорт пшеницы, имеющей темный стебель. «Красноголуша - это колос красный у ей» (Slovar' russkikh narodnykh govorov, 1979: 182);

кукуша - растение Orchis maculata L., сем. орхидных; ятрышник пятнистый; «трава эта растет большею частью по берегам рек, а иногда в лесах. Она имеет раздвоенный корень - один белый, а другой черный, лист ее усеян желтыми пятнышками» (Slovar' russkikh narodnykh govorov, 1980: 48).

Важным здесь является сложный опосредованный процесс номинации: если в первом случае актуализируется признак растения через строение тела человека и цветовую гамму, то во втором случае через соотнесение с птицей, имеющей схожий цветовой облик.

Актуализация формы растения через мотивирующую основу наблюдается в производных словах:

колпакуша - гриб Agaricus comatus (Slovar' russkikh narodnykh govorov, 1978: 193);

макуша - растение Trifolium agrarium L.; полевой трилистник, клевер (Slovar' russkikh narodnykh govorov, 1981: $315)$;

метлуиа - растение, «метлуша на любом месте растет» (Slovar' russkikh narodnykh govorov, 1995: 235);

папуша - кукуруза, початки кукурузы (Slovar' russkikh narodnykh govorov, 1990: 210);

плоскуша - 1. рыба камбала; 2. рыба плотва; 3. растение Setaria viridis, сем. злаков; щетинник зеленый (Slovar' russkikh narodnykh govorov, 1992: 147);

простуша - сорт дыни, «названий дыни очень много, дыня - простуша» (Slovar' russkikh narodnykh govorov, 1998: 256);

ригуша - сосна с неправильно растущими ветвями (Slovar' russkikh narodnykh govorov, 2001: 102); 
хохлуша - растение из семейства розоцветных с красными ароматными ягодами, напоминающими ежевику, красная морошка (Slovar' russkikh narodnykh govorov, 2005: 206). Важность формы растения, рыбы для носителя диалекта является одним из важных признаков, именно внешний вид позволяет дифференцировать один тип от другого, тем самым облегчить процесс сбора или отлова.

Актуализация функциональных признаков представлена диалектным производным сухуща - гриб, идущий на сушку (Slovar' russkikh narodnykh govorov, 2010: 30). Здесь интересен тот факт, что номинация производится по конечному этапу обработки гриба, что позволяет говорить об актуализации практического применения, что отличает именно эти грибы от других, которые именуются, например, по производимому при обработке звуку (скрипуша 1. гриб Lactarus vellereus; 2. грибы для засолки (Slovar' russkikh narodnykh govorov, 2004: 91)) или по ценности для собирающего (дорогуша - белый гриб (Slovar' russkikh narodnykh govorov, 1985: 47)).

\section{Выводы}

Диалектная подсистема общенационального языка представляет собой альтернативный способ освоения действительности носителем диалекта. Диф- ференциальная лексика словарей русских народных говоров - вербализованная экстраполяция когнитивных процессов, охватывающих в своем функционировании все уровни языковой иерархии. Представляя собой обособленное, но не автономное языковое пространство, диалектная система оперирует при номинации лиц, объектов и субъектов своими специфичными языковыми разноуровневыми единицами. Формант -уш/а относится к их числу в силу своей уникальной семантической валентности в сфере номинации (не единственной, но одной из значимых) натурфактов, которые в силу особенностей географического положения страны и ее исторического развития могут рассматриваться как значимые элементы повседневной жизни носителя диалекта. На наш взгляд, именно словообразовательные форманты позволяют актуализировать иные, нежели в литературном языке, свойства и признаки натурфактов, тем самым создавая дихотомию литературного/диалектного оязыковленного культурного пространства. Изучение процессов словообразования в диалектной системе родного языка, процессов вербализации и экспликации как уникальных в аспекте лингвокультурологии способствует формированию этнокультурной идентичности народа, так актуальной в условиях глобализации мира.

\section{Список литературы}

Араева, И.А. (2009). Словообразовательный тип. Москва, ЛИБРОКОМ, 272 с.

Араева, И.А., Образцова, М.Н., Проскурина, А.В., Абдуллаева, Ф.Е., Гуо Лихонг (2018). Как мысль реализуется в языке: пропозиционально-фреймовая организация гнезд однокоренных слов и устойчивых словосочетаний с единым ядерным компонентом в разноструктурных языках // Сибирский филологический журнал, 7(6), 295-301.

Астахов, О.Ю. (2010). Рефлексивность идентификации в культуре XX века // Русское слово в культурно-историческом и социальном контексте: сб. статей по материалам Российской науч.практ. конф. с междунар. участием. Далянь, Кемерово, Кемер. гос. ун-т, 1, 19-29.

Евсеева, И.В., Крейдин, Г.Е. (2017). Фреймовое моделирование фрагментов лексикословообразовательных гнезд с семантикой 'заболевание' // Вестник Том. гос. ун-та. Филология, 49, $5-23$.

Образцова, М.Н. (2016). Когнитивно-дискурсивное описание гнезда однокоренных слов (на материале пчеловодческой лексики русских народных говоров). Кемерово, Кемер. гос. ун-т, 206 с.

Осадчий, М.А. (2013). Однокоренная лексика русских народных говоров: фреймовая организация гнезда. Москва, ЛИБРОКОМ, 304 с. 
Проскурина, А.В. (2010). Внутренняя форма словообразовательного типа (на материале русских народных говоров). Кемерово, Кемер. гос. ун-т, 199 с.

Рассел, Б. (2000). Человеческое познание: его сфера и границы. Москва, ТЕРРА - Книжный клуб, 464 с.

Фаломкина, И.П. (2012). Пропозиционально-фреймовое моделирование словообразовательной ниши с формантом - н/я/ (на материале русских народных говоров). Кемерово, 262 с.

Источники

Герг, А.С. (1995). Словарь русских говоров Карелии и сопредельных областей. СПб., Изд-во СПб. ун-та, 3, 394 с.

Филин, Ф.П. (1966). Словарь русских народных говоров / Академия наук СССР; Институт русского языка. Москва, Наука, 2, 317 с.

Филин, Ф.П. (1968). Словарь русских народных говоров / Академия наук СССР; Институт русского языка. Москва, Наука, 3, 362 с.

Филин, Ф.П. (1970). Словарь русских народных говоров / Академия наук СССР; Институт русского языка. Москва, Наука, 6, 360 с.

Филин, Ф.П. (1972). Словарь русских народных говоров / Академия наук СССР; Институт русского языка. Москва, Наука, 7, 356 с.

Филин, Ф.П. (1972). Словарь русских народных говоров / Академия наук СССР; Институт русского языка. Москва, Наука, 8, 370 с.

Филин, Ф.П. (1978). Словарь русских народных говоров / Академия наук СССР; Институт русского языка. Москва, Наука, 14, 376 с.

Филин, Ф.П. (1979 Словарь русских народных говоров / Академия наук СССР; Институт русского языка. Москва, Наука, 15, 400 с.

Филин, Ф.П. (1980). Словарь русских народных говоров / Академия наук СССР; Институт русского языка. Москва, Наука, 16, 378 с.

Филин, Ф.П. (1981). Словарь русских народных говоров / Академия наук СССР; Институт русского языка. Москва, Наука, 17, 384 с.

Филин, Ф.П. (1990 Словарь русских народных говоров / Академия наук СССР; Институт русского языка. Москва, Наука, 25, 354 с.

Паникаровская, Т.Г. (1985). Словарь вологодских говоров. Вологда, Изд-во Вологод. гос. пед. ин-та, 2, 184 с.

Паникаровская, Т.Г. (2005). Словарь вологодских говоров. Вологда, Изд-во Вологод. гос. пед. ин-та, 11, 220 с.

Сороколетов, Ф.П. (1992). Словарь русских народных говоров / Российская академия наук. Институт лингвистических исследований. СПб., Изд-во СПб. Наука, 27, 402 с.

Сороколетов, Ф.П. (1998). Словарь русских народных говоров / Российская академия наук. Институт лингвистических исследований. СПб., Изд-во СПб. Наука, 32, 272 с.

Сороколетов, Ф.П. (2001). Словарь русских народных говоров / Российская академия наук. Институт лингвистических исследований. СПб., Изд-во СПб. Наука, 35, 362 с.

Сороколетов, Ф.П. (2010). Словарь русских народных говоров / Российская академия наук. Институт лингвистических исследований. СПб., Изд-во СПб. Наука, 43, 350 с.

\section{References}

Araeva, L.A. (2009). Slovoobrazovatel'nyi tip [Derivational type]. Moscow, LIBROKOM, 272 p.

Araeva, L.A., Artemova, T.V., Bulgakova, O.A., Obraztsova, M.N. \& Kreidlin, G.E. (2015). Propositional frame-based description of fragments of the Teleut linguistic worldview. In Review of European Studies, 7 (6), 295-301.

Araeva, L.A., Obraztsova, M.N., Proskurina, A.V., Abdullaeva, F.E. \& Guo Lihong (2018). Kak mysl' realizuetsia v iazyke: propozitsional'no-freimovaia organizatsiia gnezd odnokorennykh slov i ustoichivykh

$$
-754-
$$


slovosochetanii s edinym iadernym komponentom $\mathrm{v}$ raznostrukturnykh iazykakh [How a thought is verbalized in the language: the propositional-frame organization of nests of single-root words and idioms with a single nuclear component in multi-structural languages]. In Sibirskii filologicheskii zhurnal [Siberian Journal of Philology], 4, 205-2015.

Astakhov, O. Iu. (2010). Refleksivnost' identifikacii v kul'ture XX veka [Reflexivity of identification in the culture of the twentieth century]. In Sbornik statej po materialam Rossijskoj nauchno-prakticheskoj konferencii s mezhdunarodnym uchastiem «Russkoe slovo v kul'turno-istoricheskom i social'nom kontekste» [Collection of articles based on the materials of the Russian scientific and practical conference with international participation «The Russian word in the cultural, historical and social context»]. Dalyan', Kemerovo, KemGUKI, 1, 19-29.

Evseeva, I.V., Kreidlin, G.E. (2017). Freimovoe modelirovanie fragmentov leksikoslovoobrazovatel'nykh gnezd s semantikoi 'zabolevanie' [Frame modeling of lexical word-formation nests fragments with the semantics «disease»]. In Vestnik Tomskogo gosudarstvennogo universiteta. Filologia [Bulletin of Tomsk State University], 49, 5-23.

Falomkina, I.P. (2012). Propozitsional'no-freimovoe modelirovanie slovoobrazovatel'noi nishi s formantom - n/ia/ (na material russkikh narodnykh govorov) [Propositional frame modeling of the word-formation niche with formant -H/я/ in Russian folk dialects]. Kemerovo, 262 p.

Obraztsova, M.N. (2016). Kognitivno-diskursivnoe opisanie gnezda odnokorennykh slov (na material pchelovodcheskoi leksiki russkikh narodnykh govorov) [Cognitive-discursive description of the nest of oneroot words (the beekeeping vocabulary of Russian folk dialects)]. Kemerovo, Kemerovo State University, $206 \mathrm{p}$.

Osadchii, M.A. (2013). Odnokorennaia leksika russkikh narodnykh govorov: freimovaia organizatsiia gnezda [Cognate vocabulary of Russian folk dialects: Frame structure nest]. Moscow, LIBROKOM, 304 p.

Proskurina, A.V. (2010). Vnutrenniaia forma slovoobrazovatel'nogo tipa (na materiale russkih narodnyh govorov) [Internal form of word-formation type in Russian folk dialects]. Kemerovo, Kemerovo State University, $199 \mathrm{p}$.

Russel, B. (2000). Chelovecheskoe poznanie ego sfery i granicy [Human knowledge: its scope and limits]. Moscow, Terra-Knizhnyy klub, 464 p.

\section{Sources}

Gerg, A.S. (1995). Slovar' russkikh govorov Karelii i sopredelnykh oblastei [Dictionary of Russian dialects of Karelia and adjacent areas]. St. Petersburg, Izd-vo S.-Peterb. un-ta, 3, 394 p.

Filin, F.P. (1966). Slovar' russkikh narodnykh govorov / Akademiia nauk SSSR; Institut russkogo iazyka [Dictionary of Russian folk dialects / USSR Academy of Sciences; Institute of Russian Language, Vocabulary]. Moscow, Nauka, 2, 317 p.

Filin, F.P. (1968). Slovar' russkikh narodnykh govorov / Akademiia nauk SSSR; Institut russkogo iazyka [Dictionary of Russian folk dialects / USSR Academy of Sciences; Institute of Russian Language, Vocabulary]. Moscow, Nauka, 3, 362 p.

Filin, F.P. (1970). Slovar' russkikh narodnykh govorov / Akademiia nauk SSSR; Institut russkogo iazyka [Dictionary of Russian folk dialects / USSR Academy of Sciences; Institute of Russian Language, Vocabulary]. Moscow, Nauka, 6, 360 p.

Filin, F.P. (1972). Slovar' russkikh narodnykh govorov / Akademiia nauk SSSR; Institut russkogo iazyka [Dictionary of Russian folk dialects / USSR Academy of Sciences; Institute of Russian Language, Vocabulary]. Moscow, Nauka, 7, 356 p.

Filin, F.P. (1972). Slovar' russkikh narodnykh govorov / Akademiia nauk SSSR; Institut russkogo iazyka [Dictionary of Russian folk dialects / USSR Academy of Sciences; Institute of Russian Language, Vocabulary]. Moscow, Nauka, 8, 370 p.

Filin, F.P. (1978). Slovar' russkikh narodnykh govorov / Akademiia nauk SSSR; Institut russkogo iazyka [Dictionary of Russian folk dialects / USSR Academy of Sciences; Institute of Russian Language, Vocabulary]. Moscow, Nauka, 14, 376 p. 
Filin, F.P. (1979). Slovar' russkikh narodnykh govorov / Akademiia nauk SSSR; Institut russkogo iazyka [Dictionary of Russian folk dialects / USSR Academy of Sciences; Institute of Russian Language, Vocabulary]. Moscow, Nauka, 15, 400 p.

Filin, F.P. (1980). Slovar' russkikh narodnykh govorov / Akademiia nauk SSSR; Institut russkogo iazyka [Dictionary of Russian folk dialects / USSR Academy of Sciences; Institute of Russian Language, Vocabulary]. Moscow, Nauka, 16, 378 p.

Filin, F.P. (1981). Slovar' russkikh narodnykh govorov / Akademiia nauk SSSR; Institut russkogo iazyka [Dictionary of Russian folk dialects / USSR Academy of Sciences; Institute of Russian Language, Vocabulary]. Moscow, Nauka, 17, 384 p.

Filin, F.P. (1990). Slovar' russkikh narodnykh govorov / Akademiia nauk SSSR; Institut russkogo iazyka [Dictionary of Russian folk dialects / USSR Academy of Sciences; Institute of Russian Language, Vocabulary]. Moscow, Nauka, 25, 354 p.

Panikarovskaia, T.G. (1985). Slovar' vologodskikh govorov [Dictionary of Vologda dialects]. Vologda, Izd-vo Vologodskogo gosudarstvennogo pedagogicheskogo instituta, 2, $184 \mathrm{p}$.

Panikarovskaia, T.G. (2005). Slovar' vologodskikh govorov [Dictionary of Vologda dialects]. Vologda, Izd-vo Vologodskogo gosudarstvennogo pedagogicheskogo instituta, 11, $220 \mathrm{p}$.

Sorokoletov, F.P. (1992). Slovar' russkikh narodnykh govorov / Rossiiskaia akademiia nauk; Institut lingvisticheskikh issledovanii [Dictionary of Russian folk dialects / Russian Academy of Sciences; Institute of Linguistic Studies]. St. Petersburg, Nauka, 27, 402 p.

Sorokoletov, F.P. (1998). Slovar' russkikh narodnykh govorov / Rossiiskaia akademiia nauk; Institut lingvisticheskikh issledovanii [Dictionary of Russian folk dialects / Russian Academy of Sciences; Institute of Linguistic Studies]. St. Petersburg, Nauka, 32, 272 p.

Sorokoletov, F.P. (2001). Slovar' russkikh narodnykh govorov / Rossiiskaia akademiia nauk; Institut lingvisticheskikh issledovanii [Dictionary of Russian folk dialects / Russian Academy of Sciences; Institute of Linguistic Studies]. St. Petersburg, Nauka, 35, 362 p.

Sorokoletov, F.P. (2010). Slovar' russkikh narodnykh govorov / Rossiiskaia akademiia nauk; Institut lingvisticheskikh issledovanii [Dictionary of Russian folk dialects / Russian Academy of Sciences; Institute of Linguistic Studies]. St. Petersburg, Nauka, 43, 350 p. 